\title{
Exploring COBIT Processes for ITG in Saudi Organizations: An empirical Study
}

\author{
Ahmad A. Abu-Musa. Tanta University. Egypt. aabomosa@kku.eud.sa
}

\begin{abstract}
Control Objectives for Information and Related Technology (COBIT) has become one of the most important guidelines for information technology governance (ITG), which provides organizations with a useful tool to start evaluating their own ITG systems. COBIT introduces an ITG framework and supporting toolset that allows IT managers to bridge the gap between control requirements, technical issues and business risks. The objective of this study is to investigate the formality, auditing, responsibility and accountability of implementing COBIT processes for ITG in Saudi organizations. An empirical survey, using a self-administered questionnaire, was conducted to achieve these objectives. Five hundred questionnaires were distributed to a sample of Saudi organizations in a selected number of Saudi cities. One hundred and twenty seven valid questionnaires - representing a 25.4 percent response rate -were collected and analyzed using the Statistical Package for Social Sciences (SPSS) version 16. While the results of the study reveal that the majority of respondents reported that implementing ITG COBIT processes and domains is the responsibility of IT departments in Saudi organizations, most of the respondents reported that the COBIT processes and domains are neither audited nor formally conducted in their organizations. From a practical standpoint, managers and practitioners alike stand to gain from the findings of this study. The study provides useful information for senior management, IT managers, accountants, auditors, and academics to understand the implementation phase and the impact of COBIT on ITG in Saudi organizations.
\end{abstract}

Key words: COBIT, information technology, IT Governance, Saudi Arabia, empirical study. 


\section{INTRODUCTION}

Information technology (IT) has become widely integrated into most organizations. Therefore, implementing effective information technology governance (ITG) has become a necessity as many organizations have developed critical dependencies on IT for their successes (Posthumusa and Solms, 2005; Bodnar, 2006). Effective ITG helps ensure that IT supports business goals, optimizes business investment in IT, and appropriately manages IT-related risks and opportunities.

Control Objectives for Information and Related Technology (COBIT) has become one of the most important guidelines for ITG, which provides organizations with a useful tool to start evaluating their own ITG systems. COBIT introduces an ITG framework and supporting toolset that allows IT managers to bridge the gap between control requirements, technical issues and business risks (Lainhart IV, 2000; Bodnar, 2003; Hardy, 2006; and Williams, 2006). COBIT was created by the Information Systems Audit and Control Association (ISACA), and the IT Governance Institute (ITGI) in 1992. The first edition of COBIT was published in 1996; the second edition in 1998; the third edition in 2000, and the on-line edition became available in 2003. The forth edition of COBIT was issued in December 2005.

COBIT has 34 objectives which have been categorized under four domains: planning and organization, acquisition and implementation, delivery and support, and monitoring (Lainhart, 2001; Hadden, 2002; Bodnar, 2003 and 2006; Brown and Nasuti, 2005b; Violino, 2005, and Hardy, 2006). COBIT's framework also identifies which of the seven information criteria (effectiveness, efficiency, confidentiality, integrity, availability, compliance and reliability), as well as which IT resources (people, applications, technology, facilities and data) are important for the IT processes to fully support the business objective (Bodnar, 2003). COBIT is now being increasingly used as a generally accepted framework ITG by IT auditors who map to Sarbanes-Oxley (SOX) requirements. The standard is becoming vital as companies strive to comply with regulations and the requirement the SOX Act. COBIT was actually released as an IT process and control framework, linking IT to business requirements (Chan, 2004; Ramos, 2004; Brown and Nasuti, 2005b, Violino, 2006).

It is argued that the most important guidelines for ITG are COBIT, issued by the IT Governance Institute, and the Information Systems Auditing Guideline titled "IT Governance," issued by the Information Systems Audit and Control Association (Bodnar, 
2003). Williams (2006) also stated that except for COBIT, there is no non-proprietary framework that comprehensively covers the total spectrum of structures and processes relevant to ITG. However, COBIT itself is often in danger of being regarded as the "allpurpose miracle cleaner" of ITG frameworks in the way it has been promoted as ITG, process and management control and IT audit tool." According to Lainhart, (2000) COBIT is now achieving worldwide recognition as the authoritative source on ITG, IT Control Objectives, and IT Audit. It is being used globally in a variety of ways by private industry, public accounting firms, governments, and academia. It is being used by boards of directors, audit committees, chief executive officers (CEOs), heads of governmental organizations, chief information officers (CIOs), security managers, and information systems auditors.

The objective of this study is to explore the current status of the implementation of COBIT framework for ITG in Saudi organizations. It investigates and assesses the formality, auditing, and responsibility and accountability of COBIT processes for ITG in Saudi Organizations. The current study intends to develop a roadmap for Saudi organizations which looks forward to compliance with COBIT and adoption of ITG principles. The study provides useful information for senior management, IT management, accountants, auditors, and academics to understand the implementation phase and impact of COBIT on the ITG in Saudi organizations.

This study is organized in six sections as follows: the first section introduces the statement of the research problem, states the research questions, and highlights the research objectives, and the second section introduces and analyzes the literature review related to the COBIT and ITG, while section three states the research questions. Section four describes the research methodology used in the current study. In section five, the main results of the empirical survey are analyzed and discussed. Finally, the last section introduces the conclusion and recommendations for further research.

\section{LITERATURE REVIEW}

Reviewing the literature on the evaluation of ITG reveals a paucity of available studies in this area of research. According to Williams (2006) few studies have been carried out in this particular research area. These studies, however, have concentrated on the difficulties that many organizations experience in developing, implementing, maintaining and monitoring effective ITG structures and processes. 
It is argued that there are few published papers in academic literature which investigate the utilization of COBIT (Ridley et al., 2004; Brown and Nasuti, 2005b). It is also argued that COBIT and its related sources are highly investigated by many academic authors. A handful of studies that benchmark the adoption and use of COBIT have been published by peer reviewed sources (Guldentops et al., 2002; Fedorowicz, and Ulric, 1998; Tongren and Warigon, 1997). On the other hand, Brown and Nasuti (2005b) stated that the ITG Institute does provide the investigator an excellent source of case studies on COBIT outcomes. Case studies from the IT Governance Institute, as well as personal contacts in companies that are currently following COBIT, are two primary sources available to assist in the evaluation of the implementation of COBIT in an IT organization. Council (2006) also argued that despite the myriad of literature on COBIT, there existed very little rigorous research. Council (2006) addressed the shortage of COBIT research area and introduced the unexplored challenges of medium sized institutions of higher learning. He also provided guidance to practitioners for implementing ITG programs to medium sized institutions of higher education

Hardy (2006) argued that organizations need a strong governance model in place to approve, prioritize and manage IT investments on an ongoing basis. This is necessary to align IT investments with the business requirements needed to deliver IT value to an organization. The process of ITG must involve the business units at the highest level in a partnership with IT to ensure that effective strategic alignment is achieved. However, COBIT provided a useful instrument to help organizations get started evaluating their own ITG systems. The ITG self-assessment checklist helps auditors to determine each of the COBIT processes. COBIT also provides a sound approach for implementing ITG related initiatives in a well-controlled environment. It identifies a set of 34 high-level control objectives were grouped into four domains: plan and organize, acquire and implement, deliver and support, and monitor and evaluate (Hardy, 2006).

In his paper, Lainhart (2001) introduced many successful case studies belonging to different organization types that have customized COBIT for their unique needs and managed their ITG. These organizations include: Sears, Roebuck \& Co., Fidelity Investments, The Office of the State Auditor of Massachusetts, the United States Federal Financial Institutions Examination Council, Daimler-Chrysler, the United States Federal Information Systems Control Audit Manual, and the United States Critical Infrastructure Assessment Office. 
Sohal and Fitzpatrick (2002) investigated the ITG and management of information in Australian organizations using a questionnaire survey that was mailed to the most senior IT officer within the organization. The respondents were categorized into three groups based on the intensity with which the company uses information, namely high tier, medium tier and low tier industries. The findings revealed some interesting differences among the three groups regarding the measurement and accountability of IT delivery. The majority of senior IT executives surveyed believed it was imperative that their organizations addressed aligning their IT with their business strategy in the near future. The results also show that most ITG activities occur at a corporate level, and IT decision/governance responsibilities are centralized. The centralization of IT decision making activities was represented by the use of steering committees comprising senior level management or director level management who are primarily responsible for setting IT policies and strategy. Whilst the outsourcing levels amongst high tier industries in Australia were comparable to the international level, there may still be some scope for increased outsourcing.

Hadden (2002) examined the role of audit committees in monitoring IT risk using a self-administered survey, mailed to 1,000 audit committee members in US companies. The instrument was developed from the 34 high-level control objectives identified in the COBIT model. Each of the 34 high-level control objectives was grouped into one of the following four business processes: planning and organization, acquisition and implementation, delivery and support, and monitoring. The results of the study indicated that audit committee IT expertise, company size, and financial service industry classification were positively associated with perceived audit committee oversight of IT risks. The results also revealed that audit committee oversight assessments were partially affected by prior COBIT experience.

Bodnar (2003) introduced an overview of the concept of ITG as it is documented in the internal audit literature. Bodnar's article also examined the extent to which the concept of ITG is embraced by other parties who are active in this area.

In recent years, control and governance of internal services such as IT have become quite critical in organizations due to the enormous size of their expenditure. As a result, managers have faced growing pressure to measure the performance of IT departments. Several concepts have been developed during the last few years such as ITG, IT scorecards, and benchmarking that have been considered by IT and business executives. But surprisingly, a recent study by the IT Governance Institute (ITGI) that covered 335 CEOs 
and CIOs in 21 countries, reported that while more than 91 percent of executives recognize that IT is vital to the success of their businesses, more than two-thirds of CEOs were not comfortable answering questions about governance and control over their IT processes. The study validates that the major problem continues to be "the inadequate view of how well IT is performing" (Son et al. 2005).

In 2005, a survey was carried out by Price Waterhouse Coopers on behalf of the ITGI. The results of the survey revealed that 75 percent of organizations currently using COBIT found it either very useful or somewhat useful, while 15 percent of the respondents were undecided and less than 10 percent had a negative response. The main negative issue identified by the respondents was the perceived complexity of the framework (Williams, 2006).

Posthumusa and Solms (2005) discussed the need for more participation of board level in the way an organization is directed and controlled, with specific interest in IT related issues. Their paper motivates the institution of an IT oversight committee to help advising the board of directors in enhancing the ITG and other strategic IT-related issues.

In 2006, the IT Process Institute conducted a study to investigate the affect of IT controls on operations, security, and audit measures. The study was designed to explore the importance of the IT controls to improve performance by studying the top-performing IT organizations. The study aimed to identify the specific IT controls that have the greatest impact on performance improvements for organizations. The study surveyed respondents from 98 IT organizations in many industries. The survey asked a broad range of questions designed to support analysis of COBIT control activities and key operations, security, and audit performance measures. The results of the study provided empirical evidence that performance is improved when IT organizations focus ongoing audit- and control-related resources on those foundational control activities that have been proven to improve performance measures. The results of the survey revealed that the increased use of IT controls correlates with higher performance across a broad range of operations, security, and audit performance measures. The presence of a correlation between control activities and performance measures indicates that the best practices outlined in the COBIT framework improve performance measures.

In their study, Luthy and Forcht (2006) compared COBIT and COSO for the purpose of compliance with rules and regulations. The results of the comparison revealed that both COSO and COBIT take an organization-wide view. However, COBIT only considers an organization-wide view to the extent of ensuring that ITG is aligned with 
overall business objectives and organization governance. COBIT also provides very detailed IT control suggestions within its presentation of detailed control objectives. The study also concluded that COSO on its own may not provide sufficient guidance for organizations and auditors as they consider compliance with laws and regulations. The study also suggested that it may be useful, if not necessary, to use more than one framework for assessing compliance with rules and regulations.

Council (2006) investigated the difficulty of implementing COBIT's Systems Security using the case study of South Louisiana Community College (SLCC). The study examined the managerial aspects of introducing COBIT's fifth Delivery and Support process (DS5) successes, and the needs of a medium sized institution of higher education. The DS5 process pertains to ensuring network security. Council (2006) used COBIT's critical success factors, key goal indicators, key performance indicators, maturity models, audit guidelines, and diagnostic tools. The study used the general analytical approach to answer the research questions and to develop the descriptive framework for the casestudy. The study revealed that COBIT DS5 matched the environment at SLCC with a few exceptions and modifications. The study also provided a useful guidance to practitioners for implementing ITG programs in medium sized institutions of higher education.

Hardy (2006) studied the case of Unisys as one of the leading international IT service companies in the USA. Hardy studied the importance of having a standardized IT strategy to support Unisys' global operations, align the IT infrastructure with the company's overall business strategy and help comply with SOX. Unisys evaluated its options and adopted COBIT to provide an effective IT control and ITG framework. As a result of implementing COBIT, business processes within IT were improved and SOXrelated controls were established. Unisys has also utilized COBIT as a guideline for developing its approach for outsourcing work to third parties by identifying processes and tasks within the domains of COBIT that can be outsourced. The results of the study revealed that Unisys' business process within IT had improved as a result of using COBIT for ongoing SOX compliance and other ITG -related projects.

Abu-Musa (2007) performed an empirical study to explore the performance of ITG in Saudi organizations using the balanced scorecard model introduced by the ITG Institute (ITGI, 2005). The results of the study revealed that the vast majority of respondents reported the importance of ITG performance measures. A majority of them reported it had been measured, but a smaller number believe that such measures have actually been used in evaluating the ITG performance in their organizations. The results of this study 
suggest that Saudi organizations should achieve better governance of their IT in order to ensure that an organization's IT strategy is aligned with and supports the overall organization's strategy — that IT supports the organization's ability to exploit opportunities and maximize benefits. The results also suggest that Saudi organizations should use their IT resources more responsibly and manage their IT-related risks appropriately in order to champion the IT development for the success of their businesses.

Tuttle and Vandervelde (2007) empirically examined internal consistency of the conceptual model that underlies the COBIT internal control framework as it applies to an audit setting (including operational, compliance, and financial audit settings). The study investigated the auditor perceptions of audit risk related to complexity, client importance, client attention, and process risk combined to represent IT process risk in the manner asserted by COBIT. The results of the study revealed that that superimposing COBIT's conceptual model onto audit relevant assessments made by a panel of highly experienced IT auditors confirmed the internal consistency between the underlying constructs of COBIT. The results also revealed that COBIT's conceptual model predicts auditor behavior in the field related to their seeking help and giving help as evidenced by their postings to a general IT audit. From a practical standpoint, the results of the study of Tuttle and Vandervelde (2007) suggested that it is very important and potentially very useful for the audit profession to seek academic examination of its practices. The findings suggest that the COBIT framework is significantly related to overall risk assessments of the COBIT processes for which they are associated. The results should give auditors and policy-makers assurance that COBIT is an appropriate supplement to COSO in an IT setting.

Neirotti and Paolucci, (2007), analyzed the strategic value of IT in the insurance industry in the US and Europe through case studies and an analysis of 30 Italian firms. The results of the study revealed that technological and business path dependencies, along with time compression diseconomies, resulted in diversities in IT adoption dynamics due to their differences in ITG and management practice. The results also suggested that most of the firms in the Italian insurance sector increased their productivity through IT regardless of their IT management capabilities. It also showed that competitive advantages were not correlated with both IT spending levels and the type of IT investments that made general productivity growth in the insurance industry. The study also found that little attention had been given to analyzing the effect of IT management 
capabilities on firms' IT resources accumulation processes over a long-time horizon, and to considering the implications of this process on competitiveness.

Bowen et al. (2007) studied the main factors influencing the ITG effectiveness and project implementation success. They addressed the gap that exists between theoretical frameworks, prior empirical research, and contemporary practices on effective ITG. Bowen et al. (2007) developed a model of the factors influencing ITG effectiveness in an organization. Data were collected from a single case site in which the governance structural variables were studied at the corporate level and ITG process variables were studied at the project level. The results obtained supported the propositions in a small number of instances. The study suggests that to carry out more in-depth case studies across a variety of industries, as well as a large scale survey of enterprise practices would likely provide valuable insights.

\section{RESEARCH QUESTIONS}

The current study attempts to answer the following research questions:

- RQ1: Who performs COBIT processes in Saudi organizations?

- RQ2: Who is accountable for the COBIT processes in Saudi organizations?

- RQ3: Are the COBIT processes and their controls formalized in Saudi organizations?

- RQ4: Are COBIT processes audited in Saudi organizations?

- RQ5: Are there any significant differences among Saudi organizations regarding the adequacy of implemented COBIT domains and processes?

- RQ6: Are there any significant differences among respondent groups regarding the adequacy of implemented COBIT domains and processes in Saudi organizations?

\section{RESEARCH METHODOLOGY}

In this study an empirical survey, using a self-administered questionnaire (Appendix: 1), was conducted to explore and evaluate the performance and implementation of ITG in Saudi organizations. The questionnaire was developed based on the COBIT selfassessment checklist of ITG introduced in its fourth edition. The questionnaire was pretested on selected members of academic staff and accounting practitioners, and it was 
piloted on a selected sample of Saudi organizations. Comments and suggestions were considered in the development and revision of the final questionnaire. The ITG 34 highlevel control objectives were grouped into four domains: plan and organize, acquire and implement, deliver and support, and monitor and evaluate, in accordance with COBIT's domains and processes in the forth edition issued in 2005.

Five hundred copies of the revised questionnaires were randomly distributed to different organizations (manufacturing companies, merchandising companies, banks, services companies, oil and gas companies, governmental units and others) in five main cities (Al-Khoubar, Dammam, Dhahran, Jeddah and Riyadh) in Saudi Arabia. After excluding incomplete and invalid questionnaires, the research ended up with one hundred and twenty seven valid and usable questionnaires - representing a 25.4 percent response rate. The author also conducted unstructured interviews with a selected number of respondents in Saudi organizations.

A reliability test was carried out on the collected data using the Cronbach Alpha model, to explore the internal consistency of the questionnaire, based on the average inter-item correlation. The result of the reliability test shows that the questionnaire design is highly reliable, and the collected data are highly reliable and consistent (Alpha = 0.8421 ). The student test ( $\mathrm{t}$ test) was also carried out to investigate if there were any significant differences between early responses (90 questionnaires) and late responses (37 questionnaires). The results of the student test revealed no significant differences between early and late responses (at significance level $\mathrm{p}=0.05$ ), providing evidence of a representative and unbiased research sample.

The collected data was processed using the Statistical Package for Social Sciences (SPSS) version 16. Descriptive statistics of the collected data was analyzed for the purpose of understanding the main characteristics of the research variables. Nonparametric tests such as Kruskal-Wallis were carried out on the collected data to investigate the significant differences among respondent groups as well as organization types related to the investigated COBIT's processes research objects. The enclosed ITG self-assessment checklist would help managers, IT users and IT auditors to determine existence and adequacy of implementation for each of the COBIT processes in their organizations. 


\section{RESULTS AND DISCUSSION}

The collected data show that 26 of the respondents are manufacturing companies and 24 are merchandising companies, representing 20.5 percent and 18.9 percent of the total responses respectively (Table I). While 33 respondents are banks and financial institutions (26 percent) and 15 of the respondents - representing 11.8 percent of the total responses - are health care and medical organizations. 18 respondents are equality divided between the oil and gas industry and the governmental sector, representing 7.1 percent of the total response each. Finally, 11 respondents (8.7 percent of the total) belong to other organizations, such as fisheries, hotels, car rental organizations, décor and carpentry firms, publishing and printing organizations, accounting and auditing firms, construction companies and design organizations.

\begin{tabular}{|l|c|c|l|c|c|}
\hline \multicolumn{2}{|c|}{$\begin{array}{c}\text { The Research Sample According to } \\
\text { Business Type }\end{array}$} & \multicolumn{3}{c|}{ The Research Sample According to } \\
Respondent Type \\
\hline Type of Business & Frequency & Percent & \multicolumn{1}{c|}{ Job Title } & Frequency & Percent \\
\hline Manufacturing & 26 & 20.5 & Executive Manager & 13 & 10.2 \\
Merchandising & 24 & 18.9 & Internal Auditor & 25 & 19.7 \\
Banking & 33 & 26 & EDP Auditor & 11 & 8.7 \\
Health Care & 15 & 11.8 & IT Specialist & 20 & 15.7 \\
Oil and Gas & 9 & 7.1 & Controller & 11 & 8.7 \\
Government & 9 & 7.1 & Accountant & 35 & 27.6 \\
Other & 11 & 8.7 & Other & 12 & 9.4 \\
\multicolumn{1}{|c|}{ Total } & $\mathbf{1 2 7}$ & $\mathbf{1 0 0 . 0}$ & Total & $\mathbf{1 2 7}$ & $\mathbf{1 0 0 . 0}$ \\
\hline
\end{tabular}

Table 1. Research Sample

Table 1 also shows that 35 of the respondents representing 27.6 percent of the total response) are accountants and 25 respondents (19.7 percent) are internal auditors. 20 respondents (15.7 percent) are IT specialists and 11 respondents (8.7 percent) are EDP auditors. 13 respondents are executive managers, and 11 respondents (8.7 percent) are controllers.

The responses to the questionnaire, and their statistical analysis, are given in table 2 for the performing body of COBIT domains and processes to Saudi organizations, and in table 3 for the Auditable and formality of COBIT domains and processes by Saudi organizations. Both these tables are placed at the end of this paper. Figures 1 to 8 are used to illustrate features of the responses in the discussion below. 


\section{Planning and Organization of IT}

Robinson, (2005) stated that ITG should not be approached in a haphazard manner. ITG demands careful thought about who makes decisions and how those decisions are made. Invariably, not all these decisions will be favorably received by the stakeholders, so communication is vital. Implementation plans and schedules need to be formalized, and all initiatives should have executive sponsorship and be supported by all levels of leadership within the organization. Posthumusa and Solms (2005) also argued that in light of recent ITG failures, it is necessary to ascertain whether or not any currently active board committees, including the audit committee, have the expertise required to advise the board on IT matters. The results of the study reveal that the majority of the respondents reported that stating the IT strategic plan and defining information architecture are performed internally by the IT department in their organizations, 71.7 percent and 66.1 percent respectively (Figure 1). Approximately 64 percent of the total respondents confirmed that defining the IT organization and relationships is decided internally though their IT departments. Furthermore around 58 percent of the total respondents reported that determining the technological directions and managing IT investments are carried out internally through the IT departments in their organizations (Table 2).

\section{Performing body of planning and organization COBIT processes in Saudi organizations}

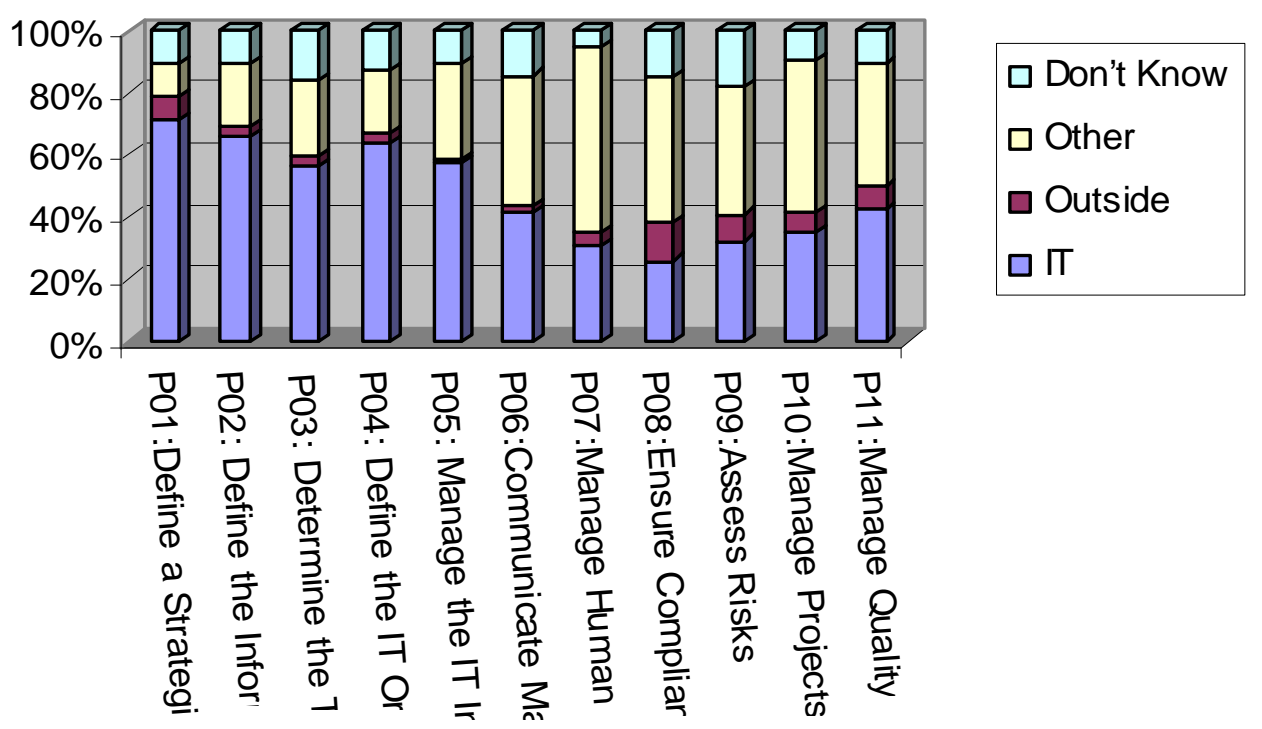

Figure 1. Performing body of planning and organization COBIT processes in Saudi organizations 
It is also observed that almost 42 percent of the respondents confirmed that communicating management aims and direction related to the IT issued is usually done though the IT department, while a similar percentage of the respondents (42.5 percent) reported that such a mission is not the responsibility of the IT department and it is usually carried out by the general management of their organizations (Figure 1). The statistical results also show that 60.3 percent of the respondents confirmed that managing IT human resources is performed by the human resources management rather than IT departments, while 30.7 percent reported that managing human resources and its activities especial training, promoting, rotating and firing of IT employees is carried out by IT departments in their organizations (Table 2).

The statistics also show that only 26 percent of the respondents reported that ensuring IT compliance with the external requirements is performed by IT departments (Table 2), 47.2 of the respondents confirmed that such compliance tests are carried out by other departments inside their organizations such as research and development departments, marketing departments, or customer services departments. While, approximately 12 percent of the respondents reported that ensuring IT compliance with the external requirements is outsourced. It is also observed that 32.3 percent of the total respondents reported that assessing IT risks is performed by IT departments, while 41 percent of the respondents reported that the task is carried out internally by internal audit departments and 8.7 percent of the total reported that assessing IT risks are carried out by a third party outside their organizations (Table 2).

The results show that 35.4 percent of the respondents believe that managing IT projects is performed by IT departments, 6.3 percent by outsiders, and approximately 49 percent of the total confirmed that it was done by the other departments in their organizations (Figure 1). The respondents are not in agreement regarding the management of IT quality; 42.5 of the respondents mentioned that it is performed by IT departments, 7.1 percent by outsiders, and 40.2 percent of the total respondents confirmed managing IT quality is carried out by other departments such as quality assurance and control in their organizations (Table 2). According to the statistical results of the KruskalWallis tests, it seems that there are no significant differences among different Saudi organizations as well as different respondent groups regarding the performing bodies of planning organization activities of COBIT processes at $\mathrm{P}=0.05$ (Table 2).

The results of the study reveal that the majority of respondents reported that planning and organization activities of COBIT processes are not audited in Saudi organizations 
(Figure 2). According to the results of the Kruskal-Wallis tests, it seems that there are no significant differences among different Saudi organizations related to auditing of COBIT' planning and organization processes at significance level $\mathrm{P}=0.05$ (Table 2). It is observed that, in organizations which have a sufficient number of IT specialists, EDP auditors pay more attention to auditing COBIT' planning and organization processes.

\section{Auditable of planning and organization of COBIT processes in Saudi organizations}

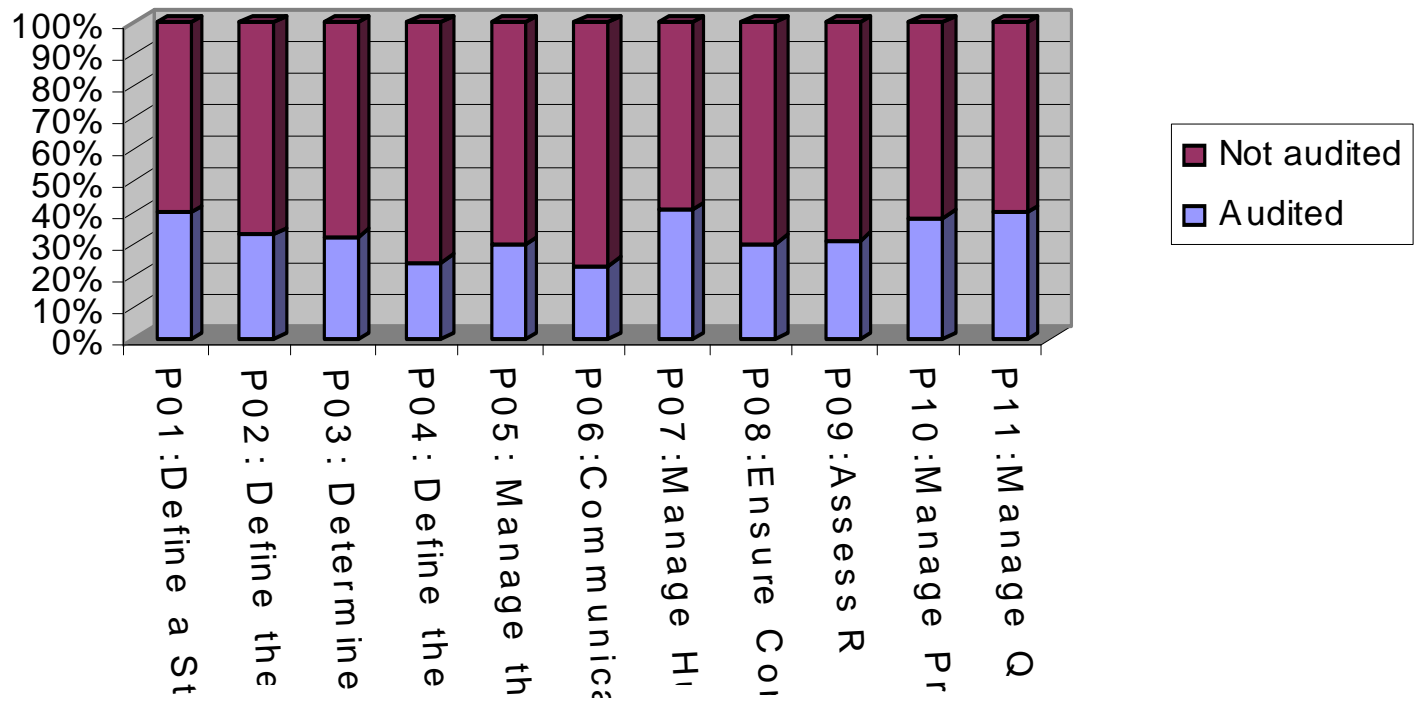

Figure 2. Auditable of planning and organization of COBIT processes in Saudi organizations

The great majority of respondents also reported that COBIT' planning and organization processes are not formally carried out in Saudi organizations (Figure 3). The results of the Kruskal-Wallis tests show significant differences in the opinions of respondent groups regarding the formality of conducing the following COBIT' planning and organization processes: defining the information architecture; determining technological direction; managing IT investment, and communicating management aims and direction in Saudi organizations at $\mathrm{P}=0.05$ (Table 2). Only EDP auditors, IT specialists, and internal auditors gave high rank to the formality of conducing COBIT' planning and organization processes in their organizations. It is suggested that informality of conducting COBIT' planning and organization processes may be due to the lack of IT specialists and EDP auditors in Saudi organizations. 


\section{Form ality of planning and organization of COBIT processes in Saudi organizations}

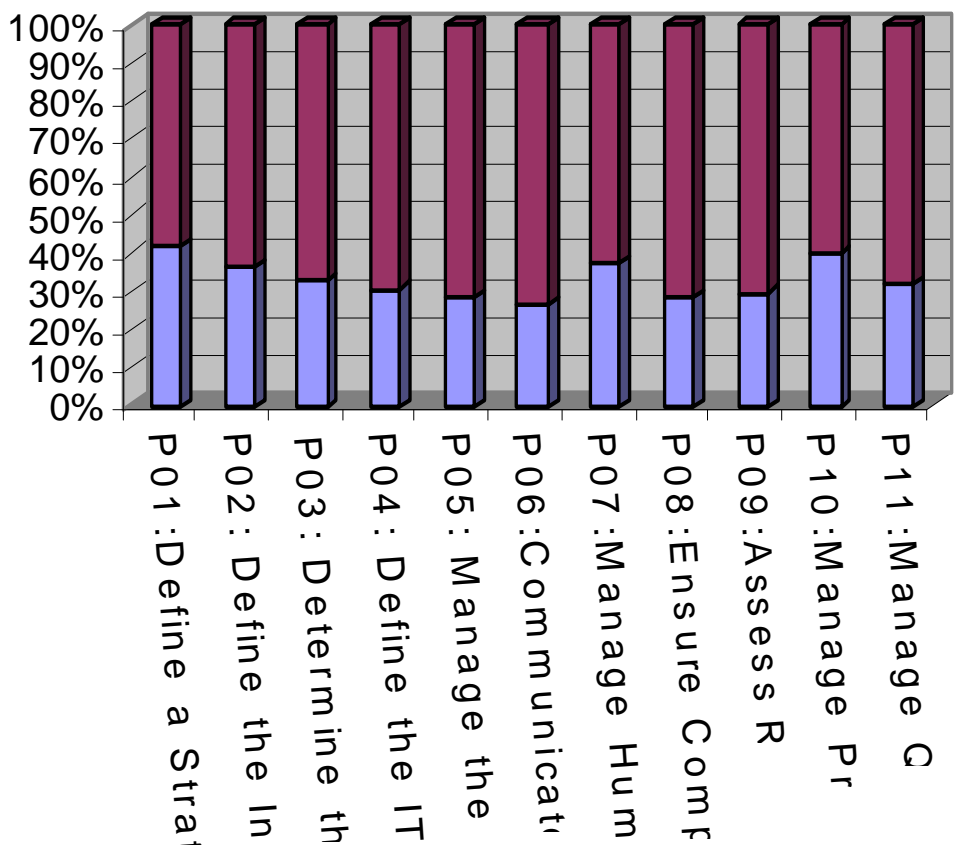

Not Formal

Formal

Figure 3. Formality of planning and organization of COBIT processes in Saudi organizations

\section{Acquisition and Implementation}

COBIT indicated that individuals at the board level and executive management are responsible for IIG as an integral part of their overall enterprise governance program. Trites (2004) raised a question of whether the directors have the expertise to evaluate if the procedures in place are appropriate or effective. He argued that even IT specialists would need to do a considerable amount of work to be able to make such an evaluation. Moreover, the directors are generally not appointed because of their expertise in evaluating controls, but rather to bring to bear their extensive business knowledge and mature judgment. This would rely on others, such as management and auditors, to determine whether the procedures in place are appropriate and effective. Normally, the auditors carry out such work and report to the management and the audit committee on the results.

The statistical results show the majority of respondents (73.2 percent) reported that developing and maintaining IT procedures are performed internally by IT departments, approximately 8 percent by outsiders, and 10 percent by other internal departments, especially internal audit departments (Figure 4). The statistics also show that 79 
respondents- representing 62.2 percent of the total- reported that acquiring and maintaining application software; acquiring and maintaining technology architecture; and installing and accrediting IT systems are performed by IT departments in their organizations (Table 2). 59.1 percent of the respondents confirmed that identifying IT solutions is always carried out by IT persons, 7.1 percent by outsiders, and 22 percent by other departments inside their business. The results also show that almost 57 percent of the respondents confirmed that managing IT changes are preformed by IT departments, 10.2 percent by outsourcing, and 29 percent by other departments within their organizations (Table 2).

The statistical results of the Kruskal-Wallis tests show no significant differences among different regarding the performing bodies of IT acquisition an implementation activities Saudi organizations at $\mathrm{P}=0.05$ (Table 2). Moreover, the results does not reveal any significant differences in the opinions of respondents groups regarding the same issues at a significance level $\mathrm{P}=0.05$ (Table 2).

\section{Performing body of acquisition and implementation COBIT processes in Saudi organizations}

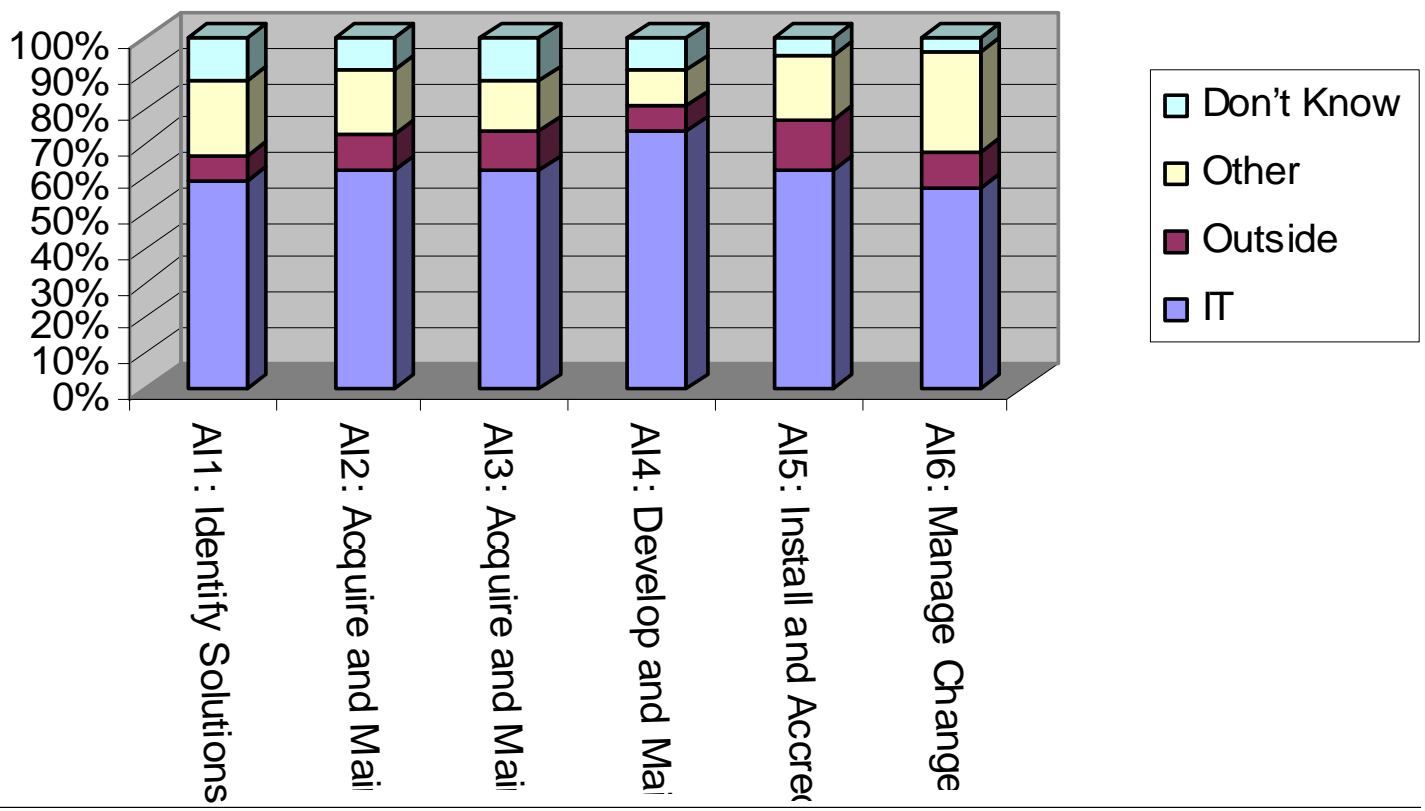

Figure 4: Performing body of acquisition and implementation of COBIT processes in Saudi organizations

Regarding the audit of the COBIT' acquisition and implementation processes, the statistics show that the majority of respondents (77.2 percent) claimed that managing IT 
changes are not audited in their organizations (Figure 5). Moreover, around 69 percent of the respondents reported that acquiring and maintaining application software, and installing and accrediting systems are not regularly audited. Almost two-thirds of the total respondents (66.1 percent and 64.6 percent respectively) reported that identify solutions, and develop and maintain it procedures are not audited in their organizations. Furthermore, around 60 percent of the total respondents confirmed that acquiring and maintaining application software activities are not audited in Saudi organizations (Table 3).

\section{Auditable of acquisition and implementation of COBIT processes in Saudi organizations}

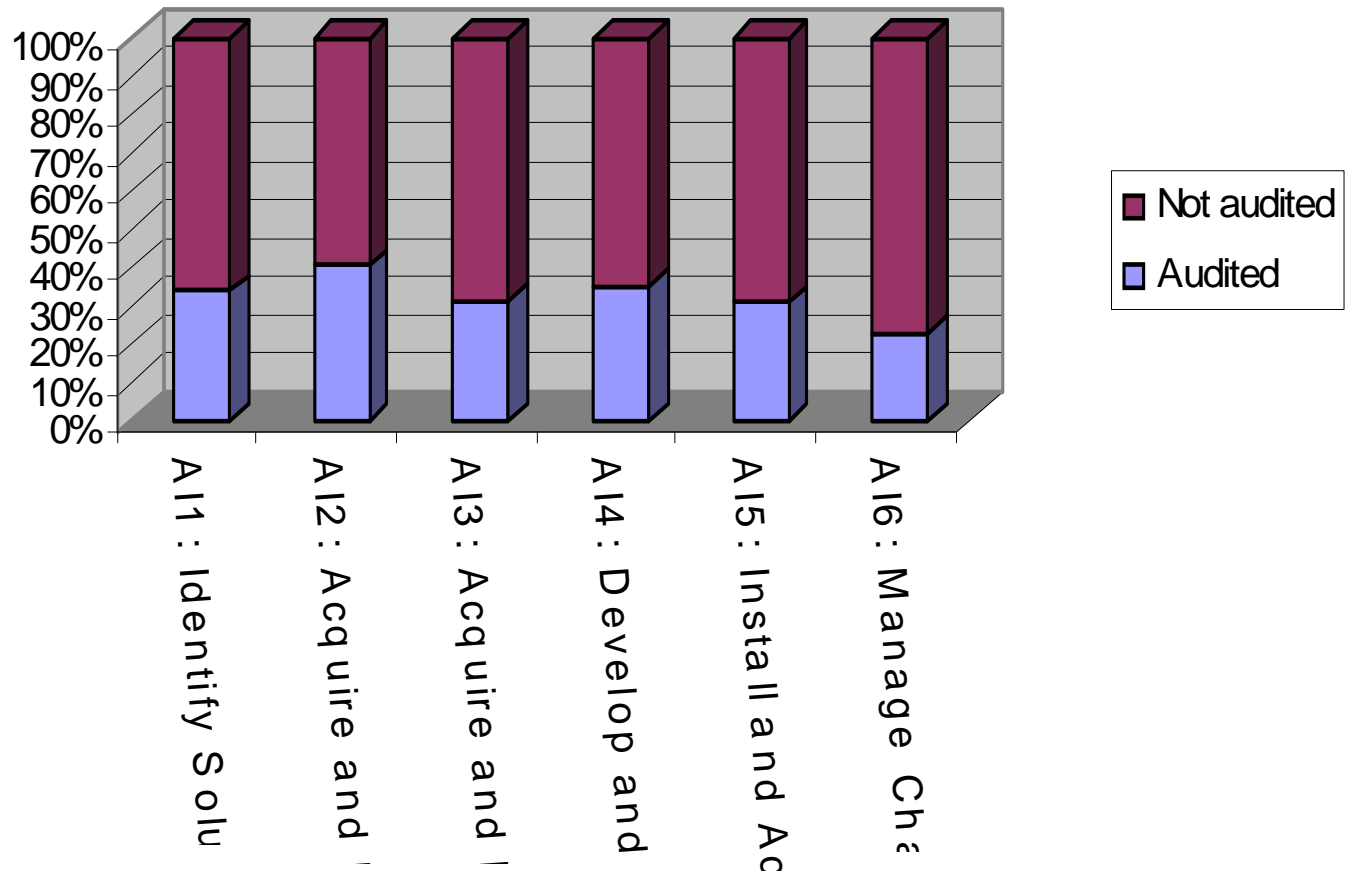

Figure 5: Audit of acquisition and implementation of COBIT processes in Saudi organizations

The statistical results of the Kruskal-Wallis tests reveal no significant differences among Saudi organizations related to auditing COBIT' acquisition an implementation processes at significance level $\mathrm{P}=0.05$. Moreover, the results show no significant differences in the perception of respondent groups regarding the audit of COBIT' acquisition and implementation processes in Saudi organizations at level $\mathrm{P}=0.05$ (Table 3).

In order to explore the formality of performing the COBIT' acquisition and implementation process in Saudi organizations, the respondents were asked to indicate whether these processes are formally or not formally conducted in their organizations. The statistics show that around 70 percent of the respondents reported that there are informal 
procedures to identify IT solutions, and to acquire and maintain application software in place. 77.2 percent of the respondents reported the existence of informal and unwritten procedures for installing and accrediting IT systems in their organizations (Figure 6). Moreover, 66.1 of the respondents reported that there are no formal written procedures for managing IT changes (Table 3). The statistical results also show that more than 60 percent of the respondents reported that there are no formal procedures for acquiring and maintaining application software, and installing and accrediting systems in their organizations (Figure 6).

According to the statistical results of the Kruskal-Wallis tests, it seems that there are no significant differences among Saudi organizations regarding the formality of conducting the COBIT' acquisition an implementation processes at $\mathrm{P}=0.05$ (Table 3). Except for acquiring and maintaining technology architecture, installing and accrediting IT systems, and managing IT changes, the results of the Kruskal-Wallis tests also show significant differences in the opinions of different respondents groups regarding the formality of conducting COBIT' acquisition an implementation in Saudi organizations at significance level $\mathrm{P}=0.05$ (Table 3).

\section{Formality of acquisition and implementation of COBIT processes in Saudi organizations}

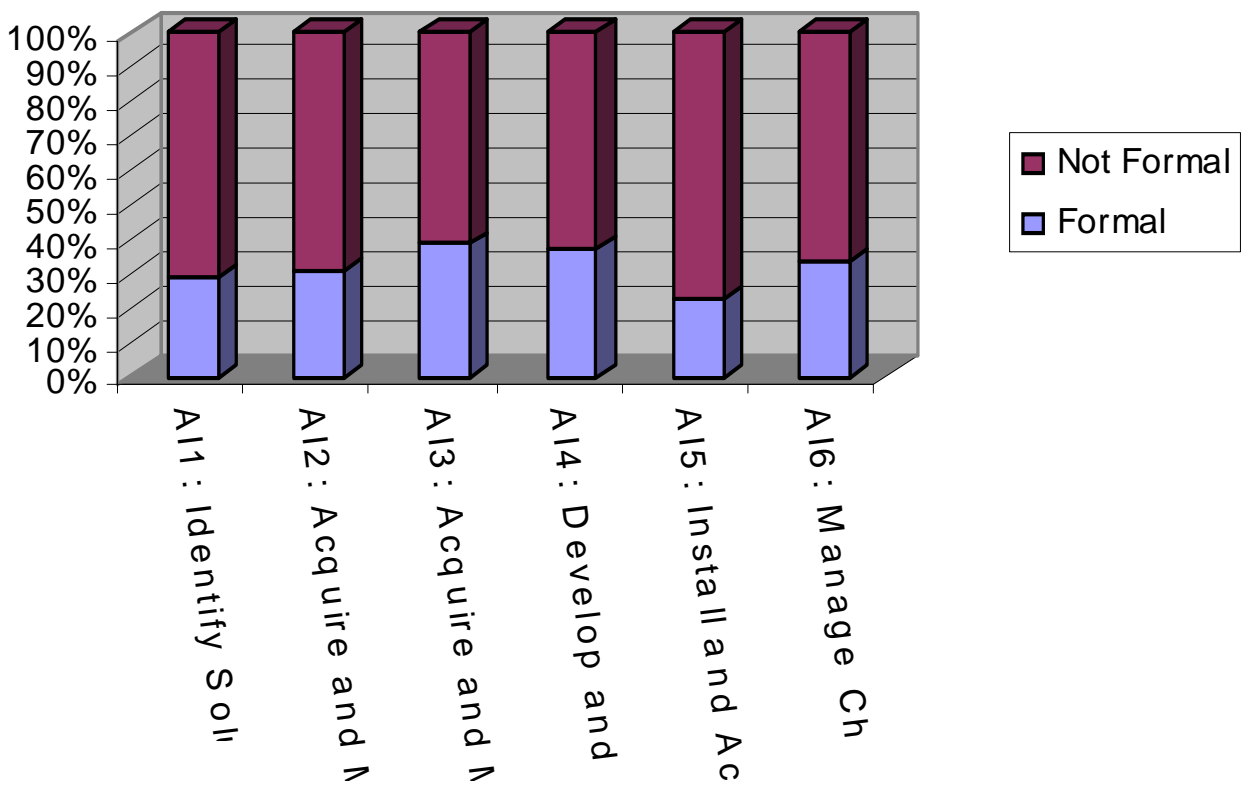

Figure 6: Formality of acquisition and implementation of COBIT processes in Saudi organizations 


\section{Delivery and Support}

COBIT encourages the creation, evaluation, and continuing improvement of IT services in order to achieve business objectives. ITG processes involve the implementation of IT management techniques and procedures in compliance with established IT strategies and policies. IT investment processes involve the identification, acquisition, implementation, and ongoing operation and maintenance activities of IT applications. As a continuous process, effective ITG provides transparent IT decision making, clear accountabilities, and acceptable and actionable IT measurements.

Figure 7 shows that managing data (69.3 percent), operations (56.7 percent), and IT configurations (59.5 percent) are mainly performed by IT departments in Saudi organizations. Approximately 67 percent of the respondents reported that assessing and advising IT customers are performed by IT departments. It is also observed that 56 percent of total respondents consider ensuring system security as a mission to be carried out by IT departments, 20.5 percent by outsiders, and almost 20 by other departments such internal audit departments and audit quality and assurance departments (Table 2). It is also observed that 57.6 percent of the respondents confirmed that managing IT problems and incidents is carried out by IT departments, and 32.3 percent of these problems and incidents are solved by other internal departments such as internal audit departments, while only 5.5 percent of such problems are dealt through outsourcing (Table 2).

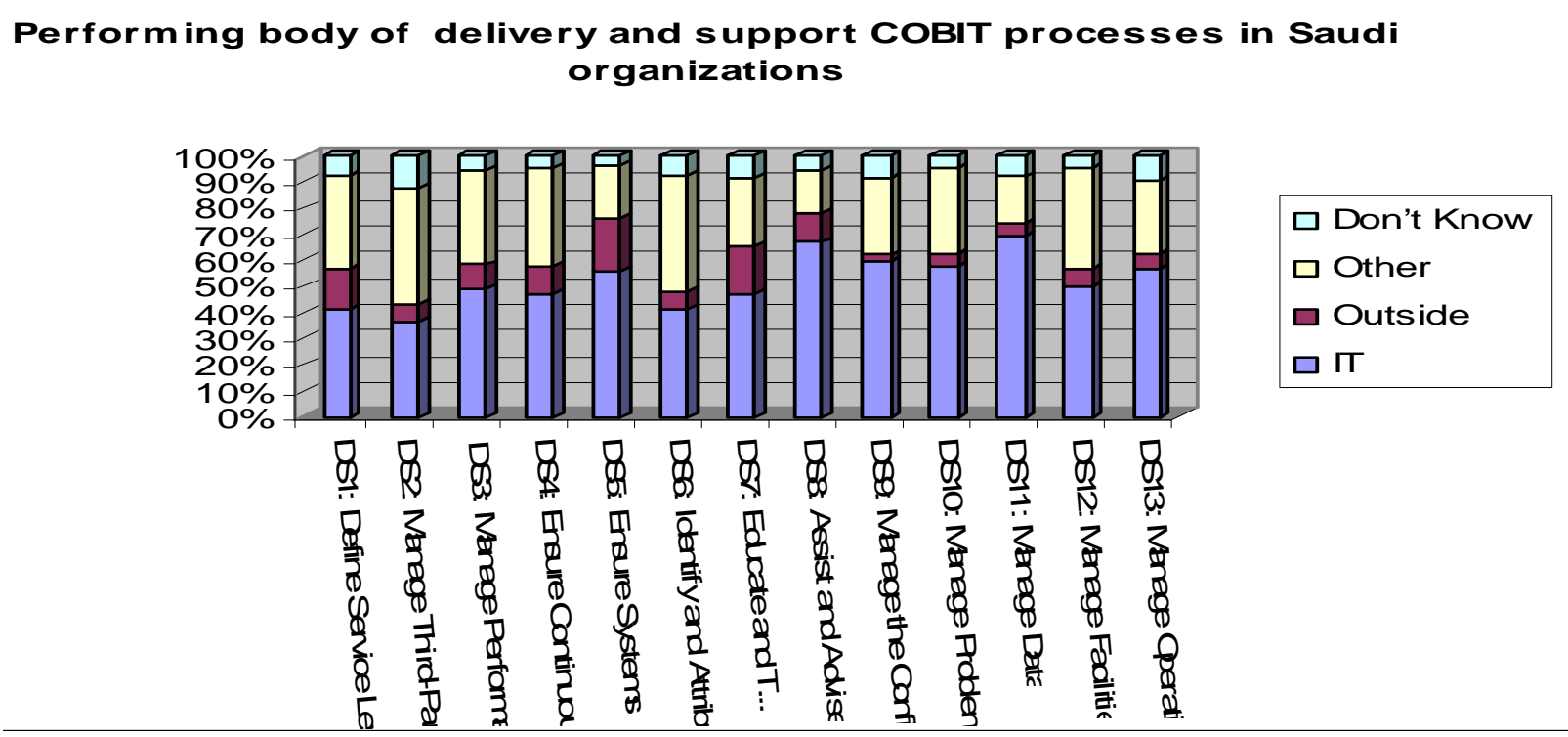

Figure 7: Performing body of delivery and support of COBIT processes in Saudi organizations 
Merely half of the respondents report that managing IT facilities are carried out by IT departments, only 6.3 percent by outsiders, and 38.6 percent by other departments in their organizations (figure 7). It is also observed that less than half of the total respondents reported that the following IT delivery and support COBIT processes are carried out by IT departments in Saudi organizations: defining IT service levels (41.7 percent), managing third-party IT services (36.2 percent), managing IT performance and capacity (48.8 percent), ensuring continuous IT services ( 47.2 percent), Identifying and attributing costs (40.9 percent), and educating and training users (47.2 percent). While the others confirmed that such IT delivery and support COBIT processes are performed either by outsiders or other internal departments in Saudi organizations (Table 2). The statistical results of the Kruskal-Wallis tests show are no significant differences among different Saudi organizations as well as different respondents groups regarding the performing bodies of IT delivery and support activities of COBIT processes at $\mathrm{P}=0.05$ (Table 2).

It is observed the vast majority of the respondents ( 80.3 percent) reported that assisting and advising IT customers programs are not audited in their organizations. It is also observed that more that 70 percent of the total respondents reported that the following COBIT processes of IT delivery and support are not audited in their organizations: defining IT service levels; managing IT third-party services, managing IT performance and capacity, identifying and attributing IT costs, educating and training IT users, managing IT configuration, and managing IT problems and incidents (Figure 8). The statistical results also revealed that more than 60 percent of the total respondents reported that managing data and IT facilities, and ensuring continuous IT services and systems security are not audited in Saudi organizations (Table 3). According to the statistical results of the Kruskal-Wallis tests, it seems that there are no significant differences among different organizations as well as different respondents groups related to auditing of COBIT processes of IT delivery and support in Saudi environment at $\mathrm{P}=$ 0.05 (Table 3). 


\section{Auditable of delivery and support of COBIT processes in Saudi organizations}

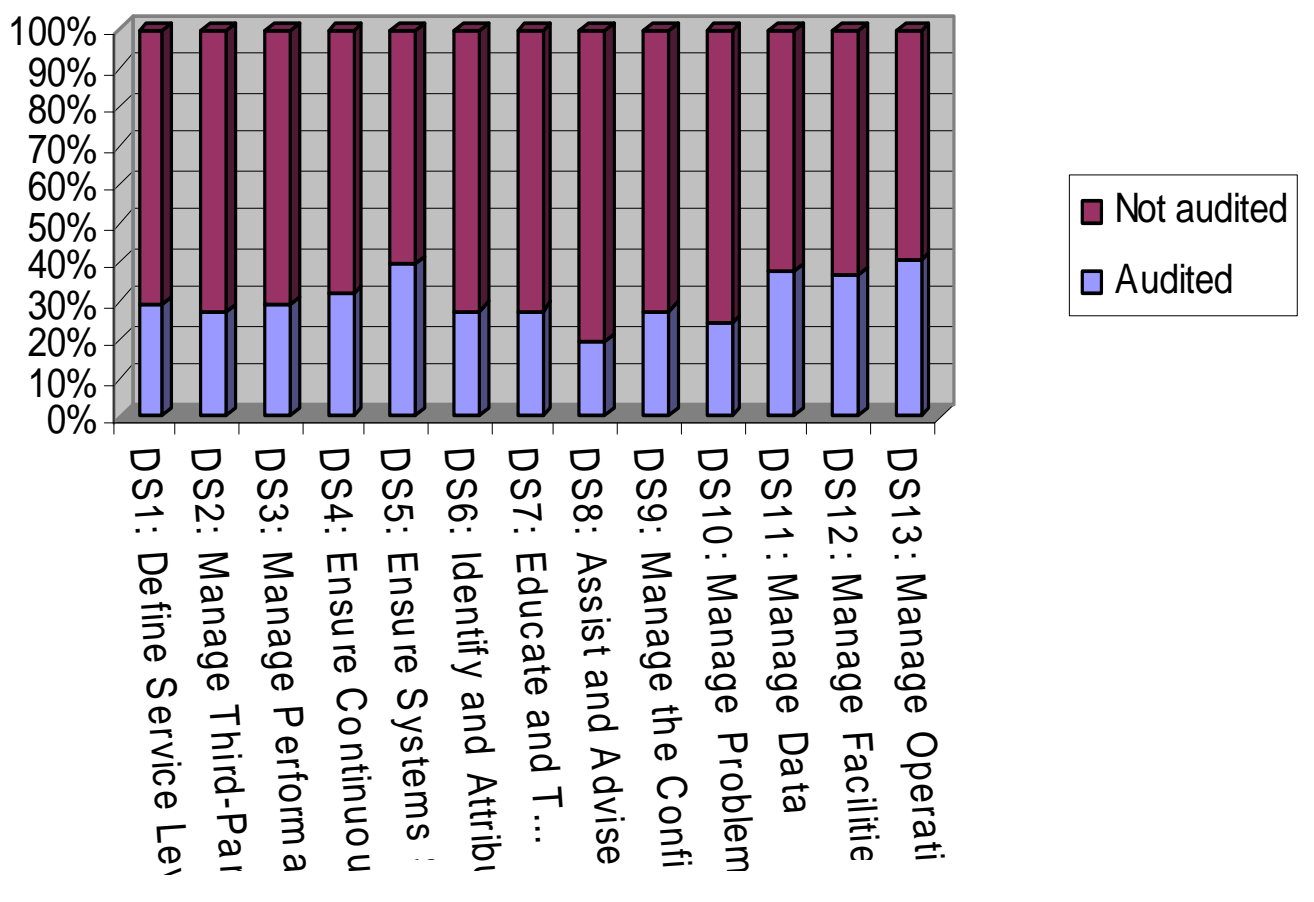

Figure 8: Audit of delivery and support of COBIT processes in Saudi organizations

The statistical results reveal that more than two-thirds of the respondents reported that the following IT delivery and support COBIT processes are not formally conducted in their organizations: defining IT service levels; managing IT third-party services, managing IT performance and capacity, ensuring continuous IT services, assisting and advising IT customers managing IT configuration, and managing IT problems and incidents (Table 3). It also observed that more than 60 percent of the respondents confirmed that the other remaining IT delivery and support COBIT processes are not formally conducted in Saudi organizations (Table 3). 


\section{Form ality of delivery and support of COBIT processes in Saudi organizations}

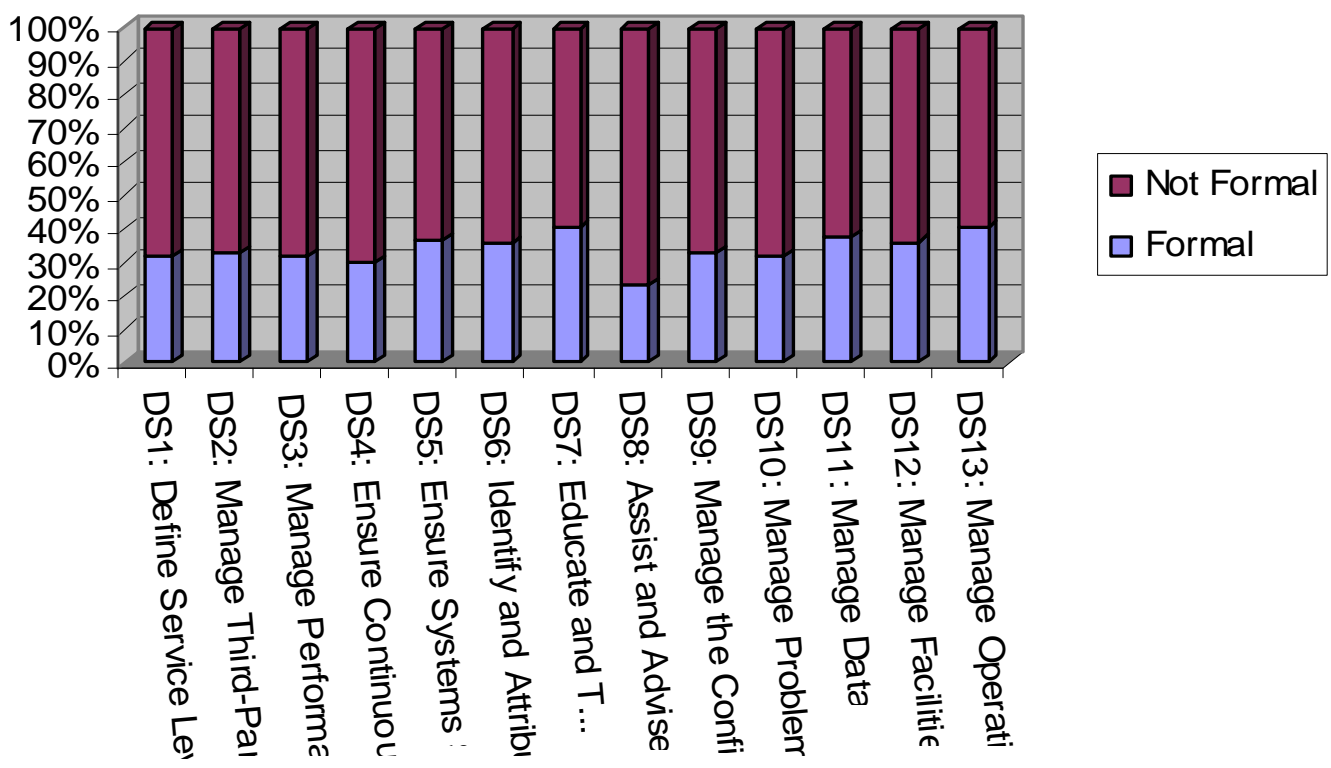

Figure 9: Formality of delivery and support of COBIT processes in Saudi organizations

The statistical results of the Kruskal-Wallis tests show significant differences among different Saudi organizations regarding the formality of ensuring systems security at a significance level $\mathrm{P}=0.05$ (Table 3). It is observed that banks and financial, health care organizations and most of services organizations have formal written security policies and procedures compared with the others. On the other hand, the results of the Kruskal-Wallis tests show significant differences in the opinions of the respondents groups regarding the existence of the formal procedures of the following IT delivery and support COBIT processes: ensuring systems security, identifying and attributing IT costs, educating and training IT users, assisting and advising IT customers, and managing IT data at a significant level $\mathrm{P}=0.05$ (Table 3 ). It is also observed that executive managers, IT specialists, EDP auditors and internal auditors confirmed the existence of formal written procedures for the above IT delivery and support COBIT processes in their organizations.

\section{Monitoring}

Trites (2004) stated that IT plays a serious role in any modern business system, and therefore, IT considerations play an important part in the controls that are necessary to preserve and protect corporate assets from misappropriation, loss and misuse. However, many, if not most, directors do not have a strong understanding of the controls issues 
raised by IT and do not even know what questions they should ask to place themselves in a position to address their responsibilities. Trites (2004) also argued that the directors cannot be expected to become experts in technology or current IT trends. Their prime focus must be to determine whether there are processes in place for the company to monitor such trends and to consider new technological developments in their strategic initiatives.

The statistical results show a high percentage of the respondents (61.4 percent) reported that monitoring IT processes is carried out by IT departments (Figure 10), 8.7 percent by outsiders through outsourcing, and 22 percent internally by other departments, especially internal audit departments in their organizations (Table 2). Regarding the assessment of adequacy of IT internal controls, the statistical results reveal that it is performed by IT departments in 42.4 percent, by outsiders 15.7 percent, and 33.1 internally through internal audit departments is Saudi organizations.

\section{Performing body of monitoring COBIT processes in Saudiorganizations}

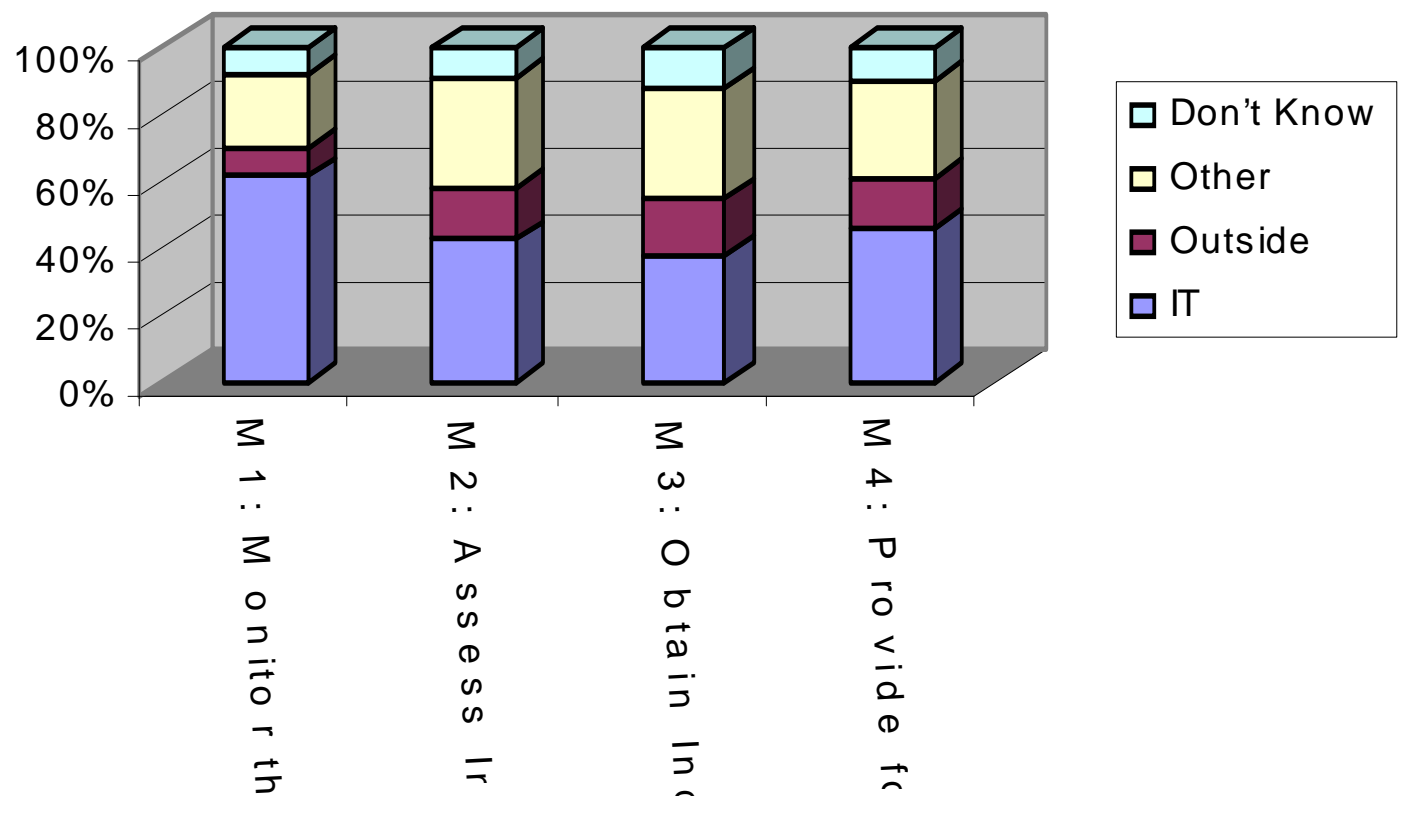

Figure 10: Performing body of monitoring of COBIT processes in Saudi organizations

It is also observed that approximately 47 percent of the total respondents reported that providing for independent audit is performed by IT departments, 15 percent by outsider 
independent auditors, and 29 percent is performed internally by the internal audit departments. The statistical results also show that 38 percent of the respondents reported obtaining IT independent assurance though IT persons, 17.3 percent through outsourcing, and 33.1 percent is carried out internally through either internal audit departments or quality and assurance controls departments in their organizations (Table 2). Again, the results of the Kruskal-Wallis tests, reveal no significant differences among Saudi organizations regarding the performing bodies of IT monitoring activities of COBIT processes at $\mathrm{P}=0.05$ (Table 2). Furthermore, no significant differences has been observed in the opinions of the respondents groups regarding the same investigated issues at $\mathrm{P}=0.05$ (Table 2).

The statistical results reveal that more than two-thirds of the total respondents reported that monitoring the IT processes, assessing the adequacy of IT internal control, and obtaining independent assurance activities is not audited in their organizations (Figure 11). The Kruskal-Wallis tests show no significant differences among Saudi organizations as well as different respondents groups related to auditing IT monitoring activities of COBIT processes at $\mathrm{P}=0.05$ (Table 3 ).

\section{Auditable of monitoring of COBIT processes in Saudi organizations}

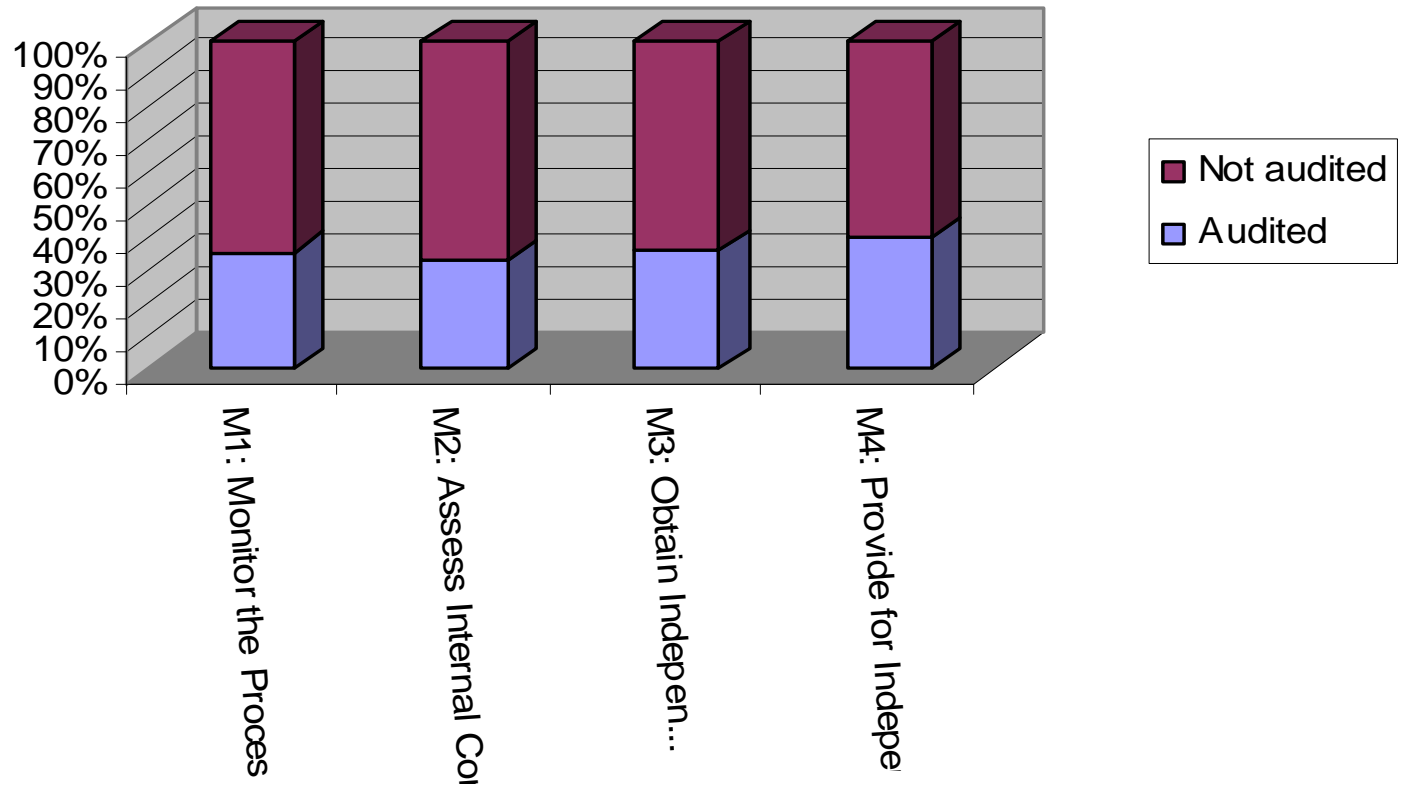

Figure 11: Audit of monitoring of COBIT processes in Saudi organizations 
It is also observed that the vast majority of respondents (more than thee-quarters) reported that IT monitoring activities of COBIT processes are informally conducted in their organizations (Figure 12), and there are no significant differences among different organizations and different respondent groups regarding theses issues in Saudi organizations at a significant level $\mathrm{P}=0.05$ (Table 3).

\section{Formality of monitoring of COBIT processes in Saudi organizations}

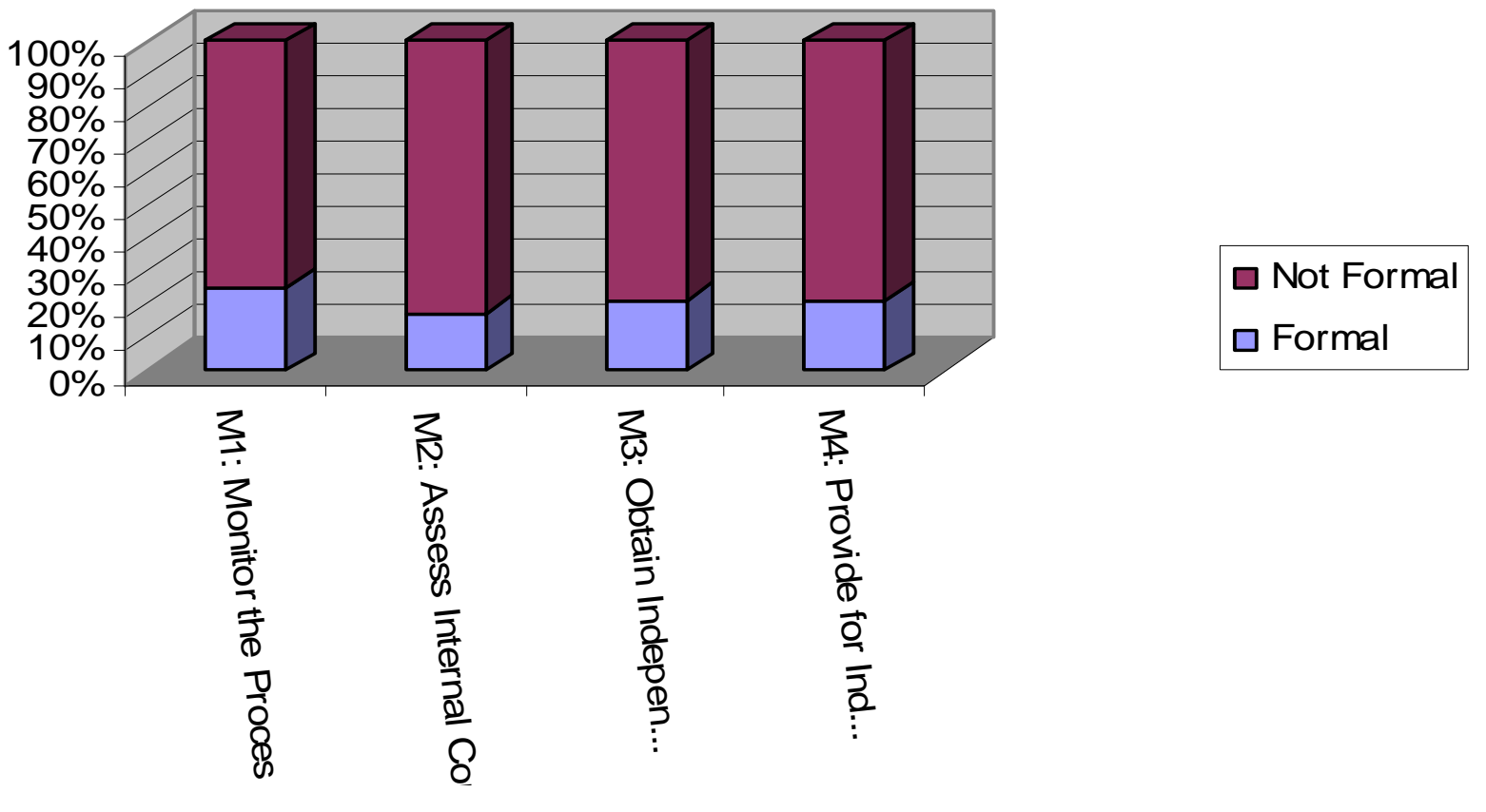

Figure 12: Formality of monitoring of COBIT processes in Saudi organizations

\section{CONCLUSION}

The current exploratory study is an attempt to empirically investigate the impact of emerging COBIT framework to evaluate and enhance the implementation of ITG in Saudi organizations. The current study investigates the formality, auditing, and responsibility and accountability of COBIT processes for ITG in Saudi Organizations. An empirical survey, using a self-administered questionnaire, was carried out to achieve this purpose. The results of the study reveal that the majority of respondents reported that IT departments have the responsibility of implementing COBIT processes and domains in their organizations. However, most of the respondents reported that the IT COBIT processes and domains are neither audited nor formally conducted in Saudi organizations. This study has provided valuable empirical results regarding the utilization of COBIT 
framework for ITG in the Saudi organizations. The results of the study enable managers and practitioners in the Saudi environment to better understand, evaluate, implement and manage ITG and champion IT for their business success. The study provides background and useful information for senior management, IT management, accountants, auditors, and academics to understand the implementation phase and impact of COBIT on the ITG in Saudi organizations. The study intends to develop a roadmap for Saudi organizations which are looking forward to compliance with COBIT and adoption of ITG principles. It is recommended to extend the scope of the current study to other countries in the Middle East (e.g. Egypt) and Gulf countries (e.g. Bahrain, Kuwait, Qatar, and United Arab Emirates) to explore the potential influence of cultural and other differences on their perception of the importance and implementation of COBIT processes in their organizations.

\section{REFERENCES}

ABU-MUSA, A. A. (2007): "Exploring Information Technology Governance (ITG) in Developing Countries: An Empirical Study", The International Journal of Digital Accounting Research, vol. 7, n.13: 71- 117.

BROWN, W.; NASUTI, F. (2005b): "What ERP systems can tell us about SarbanesOxley”, Information Management \& Computer Security, vol. 13, n. 4: 311- 327.

BOWEN, P. L.; CHEUNG M. D.; ROHDE F. H. (2007): "Enhancing IT governance practices: A model and case study of an organization's efforts", International Journal of Accounting Information Systems, vol. 8, n. 3: 191-221.

BODNAR, G. (2003): "IT Governance”, Internal Auditing, vol. 18, n. 3: 27.

BODNAR, G. (2006): “What's New in COBIT 4.0”, Internal Auditing, vol. 21, n. 4: 37- 44.

CHAN, S. (2004): "Sarbanes-Oxley: The IT dimension", The Internal Auditor, vol. 61, n. 1: 31-33.

COUNCIL, C. L. (2006): "An Investigation of a COBIT Systems Security IT Governance Initiative in Higher Education", Ph. D Dissertation Nova Southeastern University, AAT 3206177.

FEDOROWICZ, J.; ULRIC, J. (1998): "Adoption and usage patterns of COBIT: results from a survey of COBIT purchasers", Information Systems Audit \& Control Journal, vol. 6: 45-51. 
HADDEN, L. B. (2002): An investigation of the audit committee and its role in monitoring information technology risks. D.B.A., Nova Southeastern University, AAT 3074875 .

HARDY, G. (2006): "Using IT governance and COBIT to deliver value with IT and respond to legal, regulatory and compliance challenges", Information Security Technical Report, vol. 11, n. 1: 55-61.

GULDENTOPS, E.; GREMBERGEN, W.; DE HAES, S. (2002): "Control and Governance Maturity Survey: Establishing a Reference Benchmark and a SelfAssessment Tool", Information Systems Control Journal, vol. 6: 32-5.

ITGI (2003): Board Briefing on IT Governance, 2nd ed. IT Governance Institute. http://www. itgi.org/.

ITGI (2005a): Board Briefing on IT Governance, IT Governance Institute. http://www.itgi.org/.

ITGI (2005b): Governance of the Extended Organization, Bridging Business and IT Strategies. IT Governance Institute. John Wiley \& Sons, Hoboken, NJ.

LAINHART IV, J. W. (2000): "COBIT: A Methodology for Managing and Controlling Information and Information Technology Risks and Vulnerabilities", Journal of Information Systems; Supplement, vol. 14, n. 1: 21- 25.

LAINHART IV, J. W. (2001): "An IT Assurance Framework for the Future", CPA Journal, vol. 60, n. 1: 19-23.

LUTHY D.; FORCHT K. (2006): "Laws and regulations affecting information management and frameworks for assessing compliance", Information Management \& Computer Security, vol. 14, n. 2: 155-166.

NEIROTTI, P.; PAOLUCCI, E. (2007): “Assessing the Strategic Value of Information Technology: An Analysis on the Insurance Sector" Information \& Management, vol. 44, n. 6: 568-582.

POSTHUMUSA, S.; SOLMS, R. (2005): "IT oversight: an important function of corporate governance" Computer Fraud \& Security, vol. 2005, n. 6: 11-17.

RAMOS, M. (2004): How to comply with Sarbanes-Oxley Section 404. John Wiley \& Sons. Hoboken, NJ. 
RIDLEY, G.; YOUNG, J.; CAROL, P. (2004): "COBIT and its utilization: a framework from the literature", Proceedings of the 37th Hawaii International Conference on System Sciences, IEEE, New York, NY.

ROBINSON, N. (2005): "IT Excellence Starts with Governance", The Journal of Investment Compliance, vol.6, n. 3: 45-49.

SON, S.; WEITZEL, T.; LAURENT, F. (2005): "Designing a Process-Oriented Framework for IT Performance Management Systems" The Electronic Journal Information Systems Evaluation, vol. 8, n. 3: 219-228.

TONGREN, J.; WARIGON, S. (1997): "A preliminary survey of COBIT use EDP audit", Control and Security Newsletter, vol. 25, n. 3: 17-19.

TUTTLE, B.; VANDERVELDE, S. D. (2007): “An empirical examination of COBIT as an internal control framework for information technology", International Journal of Accounting Information Systems, vol. 8, n. 4: 240-263.

TRITES, G. (2004): "Director Responsibility for IT Governance" International Journal of Accounting Information Systems, vol. 5, n. 2: 89-99.

VIOLINO, B. (2005): “IT frameworks demystified”, Network World, vol.22, n. 7: 18-19.

VIOLINO, B. (2006): "Sorting the Standards", Computerworld, vol.40, n. 16: 46-47.

WILLIAMS, P. (2006): “A helping hand with IT governance", Computer Weekly, Sep. 19: 26 - 27. 